\title{
ELABORACIÓN DE UN CONCENTRADO DE USO AVÍCOLA A PARTIR DE RESIDUOS REVALORIZADOS DE LA INDUSTRIA ALIMENTARIA
}

\author{
Rubiela Quemba, Lorena Moreno, Doris Puentes, Francy Avella, William Alza. \\ Universidad Pedagógica y Tecnológica de Colombia \\ rubqr@yahoo.es
}

Manizales, 2009-04-20 (Rev. 2009-05-20)

\section{RESUMEN}

La industria alimentaria genera residuos de contenido nutricional potencialmente utilizable. Sin embargo, los desechos producidos en los centros de sacrificio, por la carencia de posibilidades de aprovechamiento, se vierten al alcantarillado. No obstante, el hollejo generado en la industria procesadora de la papa se usa como abono. Por otra parte, el residuo cachaza de la industria panelera en La Paz (Santander) se convierte en el subproducto melote, con un contenido de carbohidratos de $3 \%$. En este proyecto se revalorizaron tanto la sangre vacuna para obtener la harina de sangre que contiene proteína al $25 \%$ como el contenido ruminal que presenta el $3 \%$ de grasa y $2 \%$ de fibra. Este último se mezcló con melote y hollejo de papa que contiene $3 \%$ de fibra y $10 \%$ de proteína o con harina de sangre en proporción 3:3:4 para elaborar un subproducto revalorizado.

La sangre vacuna se procesó a harina de sangre mediante deshidratación y cocción y el contenido ruminal se integró mediante fermentación anóxica con el melote y la harina (hollejo de papa) (relaciones 3:3:4/4:3:3). Este subproducto, denominado ruminasa, se ensayará como alimento para pollo criollo en un estudio que integra la agroindustria panelera, dos centros de sacrificio y una industria de papa. Los resultados ofrecerán una alternativa de trabajo para el personal de la industria cárnica, quienes quedarán cesantes cuando se cumpla la ley 1122 de 2007 y posibilitará la elaboración de un alimento para aves accesible técnica y económicamente a los campesinos de la región mediante el aprovechamiento de residuos regionales revalorizados.

\section{PALABRAS CLAVE}

Harina de sangre, Ruminasa, Melote, Centro de sacrificio.

\section{PRODUCTION OF BIRD FEED CONCENTRATE FROM REVALUED RESIDUES OF THE FOOD INDUSTRY}

\begin{abstract}
The food industry produces waste with potentially useful nutritional content, but the debris produced in the slaughterhouses, due to the lack of ability to benefit from it, is discarded. However, the residues generated from the potato processing industry are used as fertilizer. Moreover, the sugarcane residue in La Paz (Santander) becomes treacle which has a carbohydrate content of $3 \%$. This project revalued the cattle blood to obtain blood meal with a protein content of $25 \%$, the ruminal content presents $3 \%$ fat and $2 \%$ fiber. The latter was mixed with treacle and potato skins containing $3 \%$ fiber and $10 \%$ protein or with blood meal to produce a 3:3:4 ratio revalorized subproduct. The cattle blood was processed into blood meal by means of dehydration and cooking; the rumen content was integrated by means of anoxic fermentation with treacle and flour (potato skin) (ratio 3:3:4 / 4:3:3). This subproduct, called ruminasa, will be tested as feed for creole chickens in a study that integrates the sugarcane agro-industry, two slaughterhouses and a potato industry. The results will offer a work alternative for the meat industry personnel who will become unemployed once the law 1122 of 2007 is applied. It will also allow the preparation of bird
\end{abstract}


feed technically and economically accessible to farmers in the region by means of regional revalued residues.

\section{KEY WORDS}

Blood meal, Ruminasa, Treacle, slaughterhouse.

\section{INTRODUCCIÓN}

La industria alimentaria genera residuos de contenido nutricional aprovechable; dentro de tales industrias se encuentran las empresas de sacrificio, éstas se han clasificado dentro del grupo productivo que genera subproductos a una relación del $30 \%$ del peso vivo animal (BIB). Los residuos como la sangre se vierten a los afluentes hídricos sin tratamiento previo, con un alto índice de contaminación ambiental debido, entre otras cosas, al desconocimiento del potencial nutricional de la sangre vacuna y del contenido ruminal. La agrocadena cárnica, en cuanto a la producción de carne de ganado bovino fresca o refrigerada- ocupa 1256 personas que se desempeñan en 13 empresas medianas y que, conforme a la resolución 1122 de 2007, cubrirán el territorio nacional (Espinal et al 2005). También, y dentro de la industria alimentaria, el procesado de las papas fritas para el consumo humano genera un residuo de las peladuras, denominado hollejo de papa, que contiene fibra bruta, proteína y minerales por lo que se considera un alimento valioso que se malgasta como abono.

Por otra parte la industria panelera, que se considera el segundo renglón agrario en Colombia, origina, entre otros, desechos la cachaza. Este residuo, que se deshidrata y conserva con cal al $0,66 \%$ para producir el melote con punto final del $40 \%$ de humedad, se comercializa como subproducto alimentario seguro en el sector pecuario de La Paz (Santander) por su valor nutricional, especialmente por el fósforo (alrededor de 350 ppm). El producto revalorizado posee un valor nutricional energético alto por azúcares y bajos para fibra del $2 \%$, cenizas del $3 \%$ y proteína del 3\% (Alza y Salamanca, 2007)

Es importante anotar que algunas instituciones del país han desarrollado estudios sobre el aprovechamiento, como alimento animal, de los desechos de matadero, tanto la sangre como el contenido ruminal, con implementación a nivel rural en etapas primarias. Por ejemplo, en el municipio de Siachoque, se realizaron ensayos de transformación del contenido ruminal con harina de sangre y melaza de caña azucarera para la obtención de ruminasa; sin embargo, como es un procedimiento empírico, se obtuvieron resultados negativos en el $50 \%$ de las oportunidades y los productores pecuarios de la región abandonaron esta medida de aprovechamiento.

El sistema de desagüe de la sangre se calcula para los mataderos sobre la base de 10 a 12 litros por cada bovino. El residuo está formado por plasma, fracción celular y fracción fibrilar, contiene en solución diversas sustancias como lipoproteínas, ácidos grasos no esterificados, azúcares, proteínas solubles (albúminas y globulinas) y sales minerales. La composición es de materia seca $18.4 \%$, proteína cruda $90.7 \%$, extracto etéreo $0.25 \%$, cenizas $3.7 \%$, fibra cruda $4.4 \%$. Se aprovecha el residuo de sangre bovina transformándolo en harina de sangre por dos métodos: la deshidratación que se lleva a cabo en el horno a $40^{\circ} \mathrm{C}$ con pérdida lenta de agua plasmática e intersticial durante 12 horas. La cocción y deshidratación, donde se somete a calentamiento por debajo de $80^{\circ} \mathrm{C}$ -durante un tiempo de 20-25 minutos-, con desnaturalización parcial de algunas hemoglobulinas. Para evitar que la sangre se coagule se utiliza citrato de sodio. El valor nutricional de la harina de sangre se debe a la presencia de proteínas (Calsamiglia et al 2008).

El rumen contiene una mezcla de material no digerido que tiene la consistencia de una papilla, con un color amarillo verdoso y con olor característico cuando está fresco. La fermentación anóxica de harina y melaza genera un producto de distintas características bromatológicas para tratamientos en fresco -15 días y 30 días-, mientras que el 
incremento del tiempo hasta 45 días ocasiona su deterioro (Sabogal et al, 1987). La caracterización bromatológica del mismo reporta: fibra alrededor de 2,2\%, grasa de 2,5\%, ceniza hasta 3,55\%, humedad del 40\%, proteína entre 8.74-10.62\% (Pérez et al 1994).

Las reacciones en el rumen dependen de la flora y de la fauna microbiana celulítica, que para este caso son los cocos, bacterias cuya función es hidrolizar la celulosa presente en el contenido ruminal y luego ser fermentada con la producción de ácidos grasos volátiles y proteína microbiana dentro de un sistema de temperatura constante a $39^{\circ} \mathrm{C} \mathrm{y} \mathrm{pH}$ de 6.5 . Estudios previos han demostrado que para el buen funcionamiento de esta comunidad se debe aumentar tanto la degradación de la fibra y el almidón, como la producción de los ácidos grasos volátiles con control de pH (Mungoi, 2007).

Se pretende a nivel de laboratorio revalorizar el residuo sangre para ser transformada en harina de sangre y realizar del mismo modo la revalorización del contenido ruminal a ruminasa. Para esto se prepararan mezclas de contenido ruminal, melote y harina de sangre y en otro ensayo se reemplaza la harina de sangre por hollejo de papa en distintas proporciones para la obtención de un subproducto final que se implementará como concentrado para la dieta de pollo criollo. Mensualmente, durante el segundo trimestre de 2008, se establecieron las características nutricionales de estos residuos provenientes de los centros de sacrificio (Siachoqué, Cerinza) y de la industria alimentaria (procesadora de papa).

\section{METODOLOGÍA}

La figura 1 describe el diagrama metodológico seguido durante el estudio.

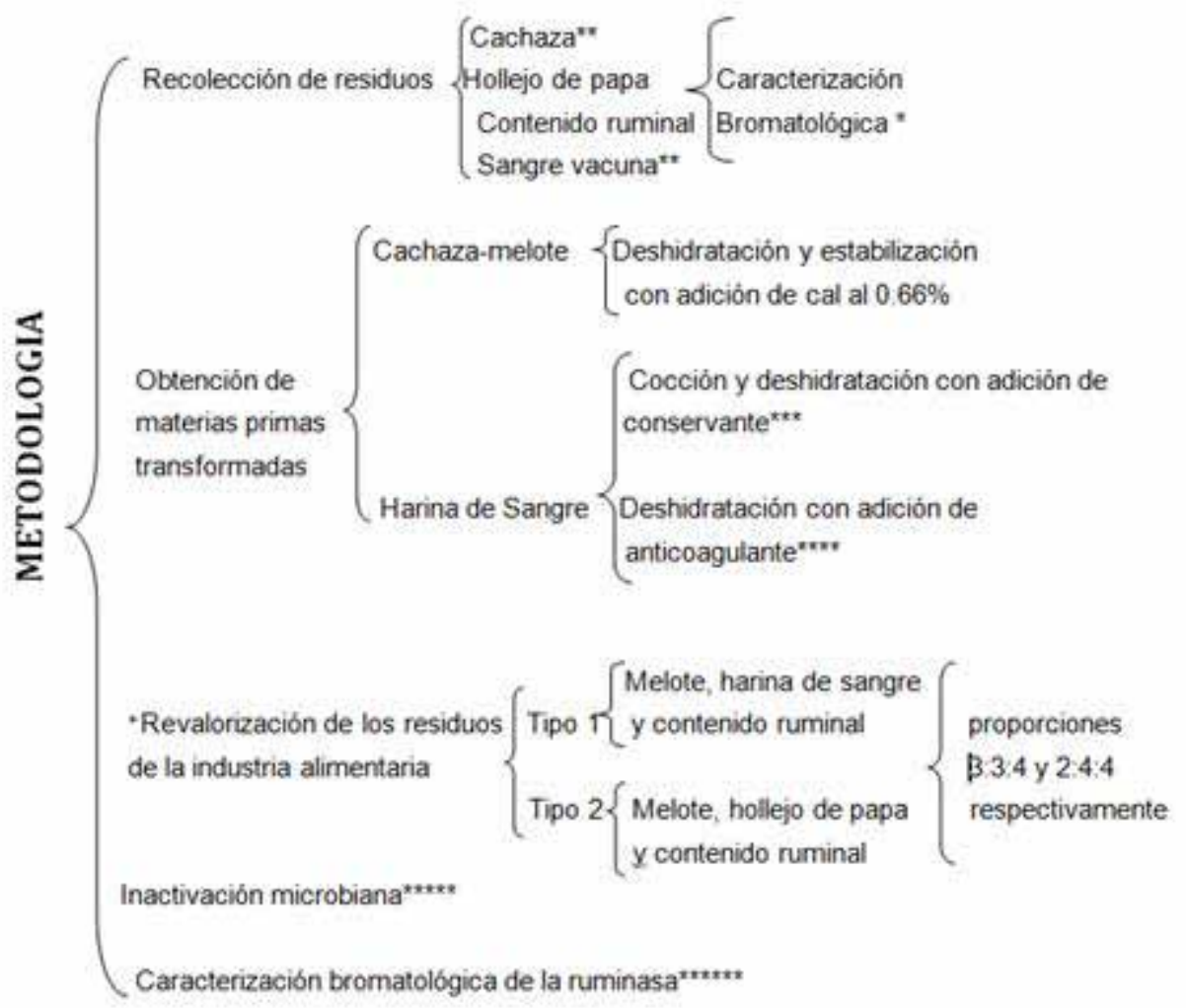

Figura 1. Diagrama metodológico del estudio.

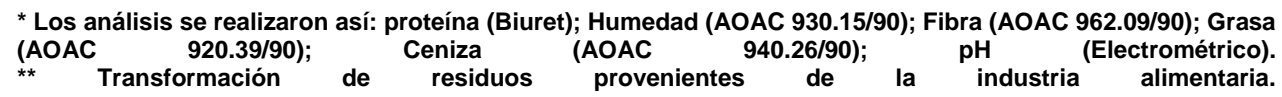


*** Las muestras frescas se llevaron a cocción a $80^{\circ} \mathrm{C}$ por $20 \mathrm{~min}$ con constante agitación y con la posterior adición en frío de las muestras de solución de ácido sulfúrico al $0.7 \%$ (conservante), continuando con el secado por deshidratación (Pond et al 2003). $\star \star \star \star$ A las muestra de sangre se le adicionaron anticoagulantes $8 \mathrm{~g} / \mathrm{L}$ de sangre vacuna; en la primera recolección se adicionó oxalato de amonio y en la segunda citrato de potasio. Se deshidrató a $40^{\circ} \mathrm{C}$ por $12 \mathrm{~h}$ en superficie metálica con altura óptima de 0,6 mm. ***** Se realizaron dos tipos de montajes para la fermentación del concentrado con las materias primas; unas de ellas fueron transformadas en rumen, harina de sangre y melote y en las otras se sustituyó la harina de sangre por el hollejo en distintas proporciones, con aquellos de uso directo en proporciones estimadas por el requerimiento fermentativo de la microbiota ruminal (Bravo et al 2000).

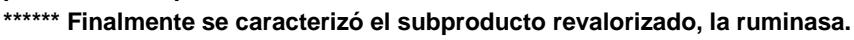

\section{RESULTADOS}

Caracterización de Residuos Alimentarios: Los residuos de sangre bovina (SRB) y contenido ruminal se obtuvieron de los centros de sacrificio de las poblaciones de Cerinza y Siachoque, durante el último semestre del año 2007 y el primer trimestre del año 2008. El resultado de la caracterización bromatológica para la sangre residual bovina sin y con anticoagulante, en promedio para cuatro muestras, se compara contra el valor teórico y se presenta en la figura 2.

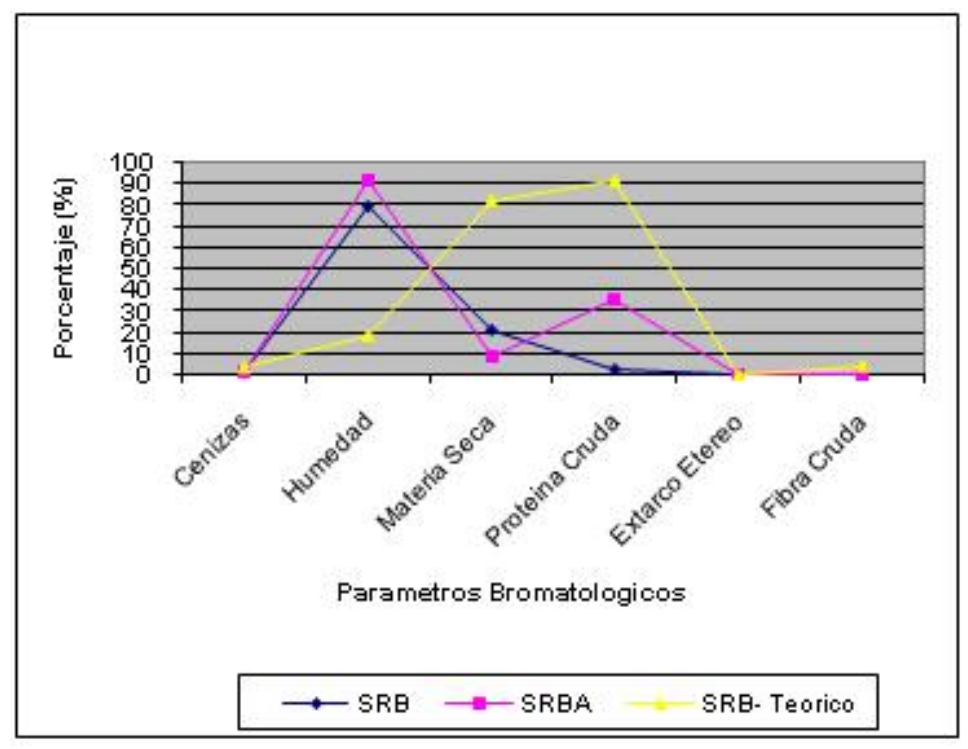

Figura 2. Comparación de las propiedades promedio de la sangre residual bovina (SRB), la sangre con anticoagulante (SRBA) y el valor teórico de SRB.

El hollejo de papa, como fuente de almidones, se obtuvo de una industria de papa frita ubicada en la ciudad de Tunja, que se deshace de este residuo como abono orgánico. Las propiedades bromatológicas se presentan en la figura 3, comparadas con otros estudios.

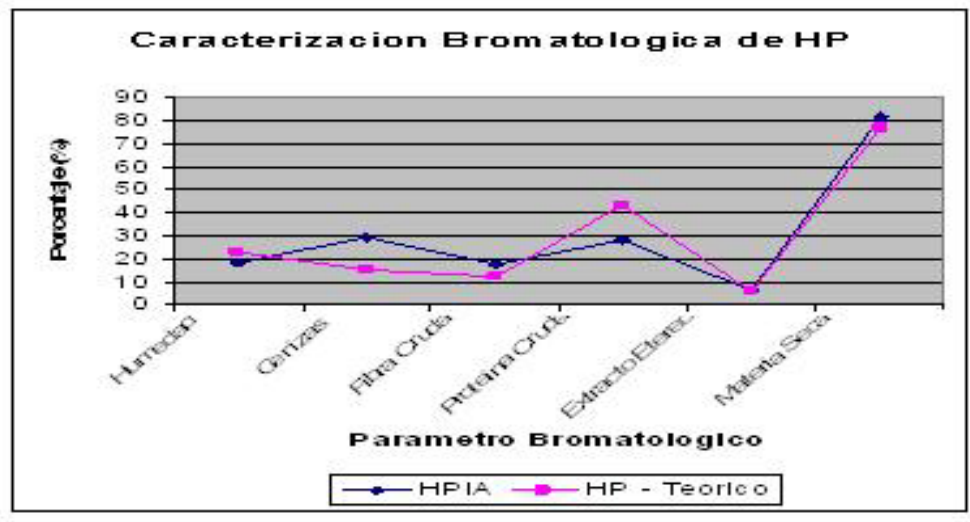


Figura 3. Caracterización del hollejo de papa residual (HPIA) de una Industria Alimentaria de Tunja.

Materias Primas Transformadas: La cachaza se transformó en melote directamente por el productor de la agroindustria panelera La Esperanza, ubicada en el Km 12 vía La Paz, durante el mes de febrero de 2008 y se entregó a los investigadores en un recipiente sellado. Para confirmar el contenido de azúcar, se encontró un porcentaje del 3\%. La harina de sangre se obtuvo por el método de cocción y deshidratación denominado tratamiento 1 , con resultados bromatológicos promedio para dos tratamientos de sangre recolectada y procesada a las 3 horas. A la sangre se le adicionó anticoagulante; se usó citrato de sodio al $8 \%$. El resultado se obtuvo de tres tratamientos en condiciones laboratorio que se presentan en la figura 4. La actividad acuosa se midió para el último proceso en ambos casos.
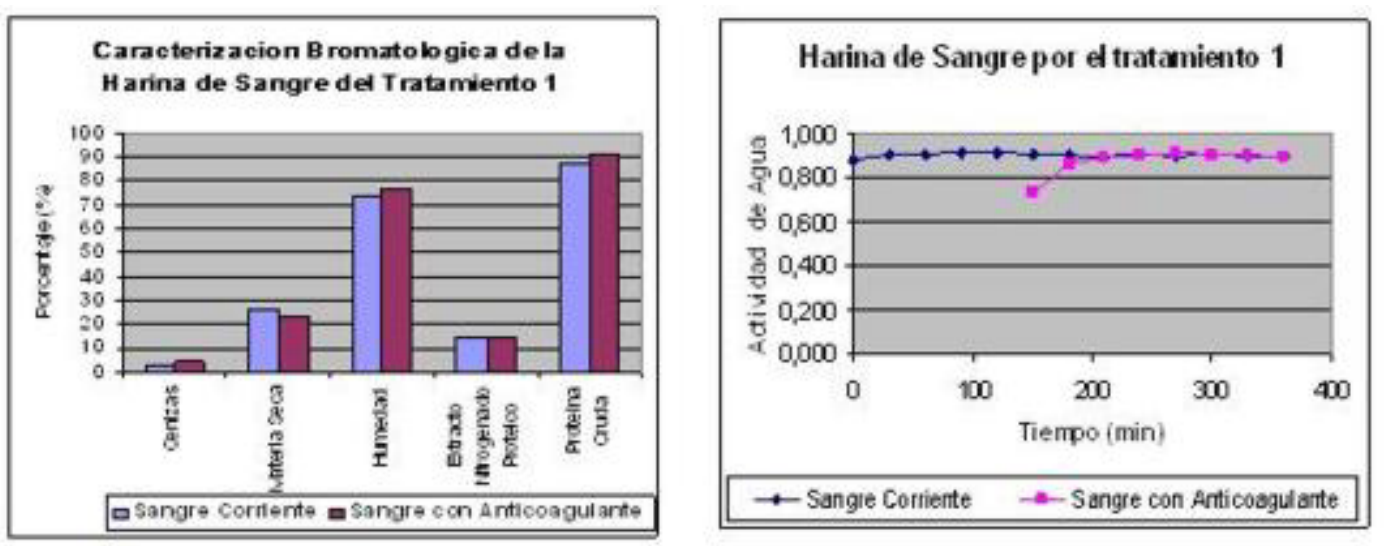

Figura 4. Harina de Sangre obtenida por cocción, seguida de deshidratación. A. Caracterización bromatológica y B. Actividad de Agua.

El tratamiento 2. La obtención de la harina de sangre se realizó mediante el método de deshidratación con resultados bromatológicos promedio para dos tratamientos de sangre recolectada y procesada a las 3 horas. Para la sangre con anticoagulante, citrato de sodio al $8 \%$, el resultado se obtuvo de tres tratamientos que se realizaron en condiciones de laboratorio (figura 5). La actividad acuosa se midió para el último proceso en ambos casos.
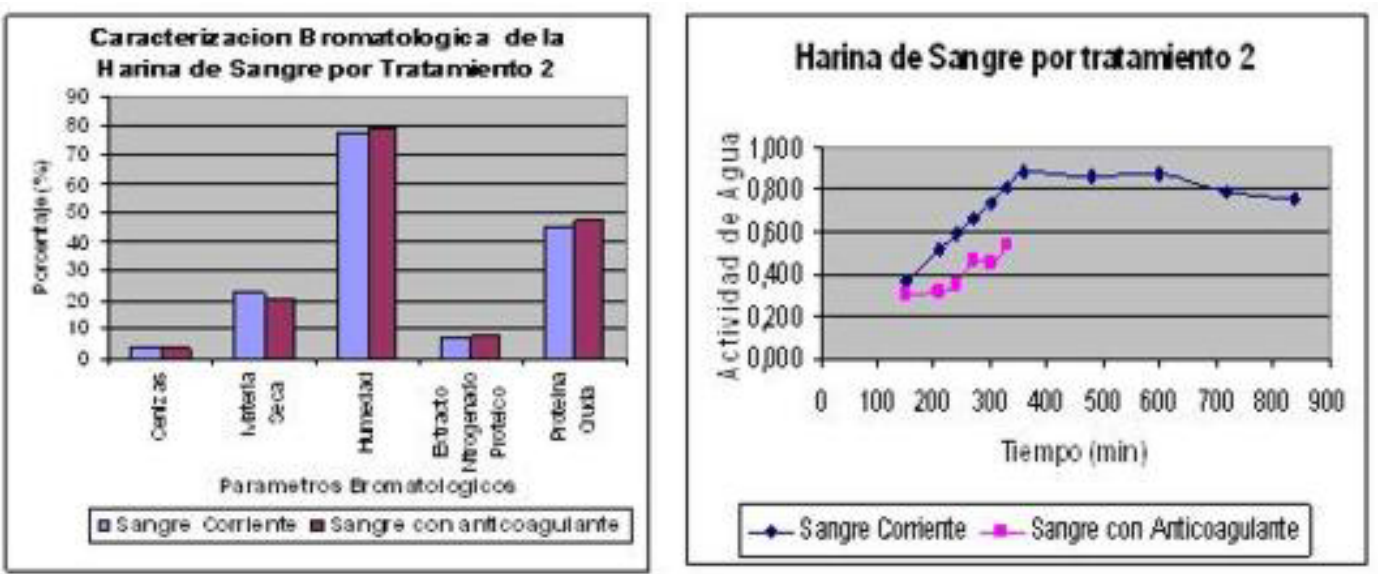

Figura 5. Harina de sangre obtenida por deshidratación. A. Caracterización bromatológica y B. Actividad de Agua. 
Revalorización de Residuos: la tabla 1 presenta los resultados obtenidos hasta el momento para ruminasa obtenida por fermentación de Melote/harina de sangre/ rumen.

Tabla 1. Caracterización concentrado de melote, harina de sangre y contenido ruminal a los 8 días.

\begin{tabular}{|l|l|l|}
\hline PARÁMETRO & $\mathbf{3 : 3 : 4}$ & $\mathbf{2 : 4 : 4}$ \\
\hline Actividad de agua & 0.847 & 0.64 \\
\hline Cenizas (\%) & 3.2 & 2.8 \\
\hline Humedad (\%) & 61.2 & 64.8 \\
\hline
\end{tabular}

\section{ANÁLISIS DE RESULTADOS}

El valor nutritivo que presenta la SRB (sangre revalorizada bovina ) no coincide con los valores de PC que son de 85 a 90\%, los que concuerdan con los obtenidos en este estudio (Pérez, 1994) y se destaca el contenido de cenizas con alrededor del 3,2\%, lo cual indica que en este desecho se encuentra un alto contenido mineral. Sin embargo, carece de fósforo y calcio que puede ser adicionado por la mezcla con melote.

\section{CONCLUSIONES}

La harina de sangre deshidratada presenta actividad de agua en el rango 0.4-0.6, en el cual existe la inhibición de microorganismos. Por lo anterior la optimización del proceso de harina de sangre obtenida por deshidratación en función del grosor de la capa de sangre con anticoagulante y conservante (ácido sulfúrico $0.7 \%$ ) Ilevada a calentamiento durante 12-14 horas corresponde a $0.6 \mathrm{~cm}$, a diferencia de Pérez, 1994.

La ruminasa con mayor proporción de melote presenta los mayores valores de actividad de agua, fuera del rango de optimización de un producto alimentario, por lo que se requiere adicionar un proceso de deshidratación adicional o esperar un tiempo mayor.

\section{BIBLIOGRAFÍA}

- Alza, William y Salamanca, Catalina. Revalorización de la cachaza en la industria panelera de La Paz (Santander). Alimentech. Universidad de Pamplona. V $5 \mathrm{~N}^{\circ} 2$ 2007.

- Mungoi, Mario Antonio. Efectos de la suplementación con malato y de la fuente de almidón sobre el rendimiento productivo de corderos de sebo. Dpt. Ciencia Animal i dels Aliments. Tesis Doctoral. universitat Autónoma de Barcelona. 2007.

- Pérez M, Patricio; Morales S, Maria Sol; Torres L, Jose Luis; Egaña M, Diaz C, Iñigo. Efecto del tiempo de ensilaje sobre las características químicas de la sangre bovina y de algunas vísceras y decomisos Avances en Medicina Veterinaria, Vol.9, No1, 1994.

- Pond, W. G. Pond K. R. y Church. D.C. Fundamentos de nutrición y alimentación de animales. Limusa-Wiley. México. 2003.

- Bravo, A. Novoa, E y Ruíz, L. Uso del contenido ruminal como parte de la dieta para pollos de engorde. revista MVZ. Vol. 4 Unicordoba. Montería p52-30. 2000.

- Donald Mc. Et Al., Los procesos de fermentación del ensilaje y su manipulación.www.fao.org/documentos/show_cdr_>p?urifile:/DOCREO/oos/x4848 6504.

- A.O.A.C. Association Of Official Analytical Chemistry. Official Methods Of Analysis $\begin{array}{lllll}\text { Of } & \text { A.O.A.C } & \text { Arlington } & 15 & \end{array}$ 